\title{
Using Foundry Waste Materials in Concrete for a More Sustainable Future
}

\author{
Anthony Torres* \\ Texas State University, USA
}

*Corresponding author: Anthony Torres, Department of Engineering

Technology, Concrete Industry Management Program, Texas State University, USA.
Received Date: September 04, 2020

Published Date: September 21, 2020

\section{Opinion}

It is the perspective of the author that the current trend in concrete materials is in the sustainability of the material. One major way of producing sustainable concretes is through the use of waste materials or other recycled materials. This is accomplished by reducing the demand for raw materials such as sand and rock and even cement in some instances. One movement is toward using waste from the steel casting (foundry) and manufacturing industries. According to recent studies, approximately 6-10 million tons of waste is produced annually by the foundry industry and estimates have shown that only $15 \%$ of the waste produced is being recycled each year [1]. The increasing scarcity of landfill space and disposal cost has fashioned a need for an alternative disposal method of this large industrial waste, and researchers have discovered that it can be used in concrete. Foundry waste can consist of many products such as spent foundry sand, slag, ash, refractory, coagulant, baghouse dust, pattern shop waste, and debris [1-4]. Of this waste a large percentage consists of spent foundry sand (SFS) from casting molds and slag from smelting of iron ore. A picture of a typical foundry waste can be seen in Figure 1 (Figure 1).

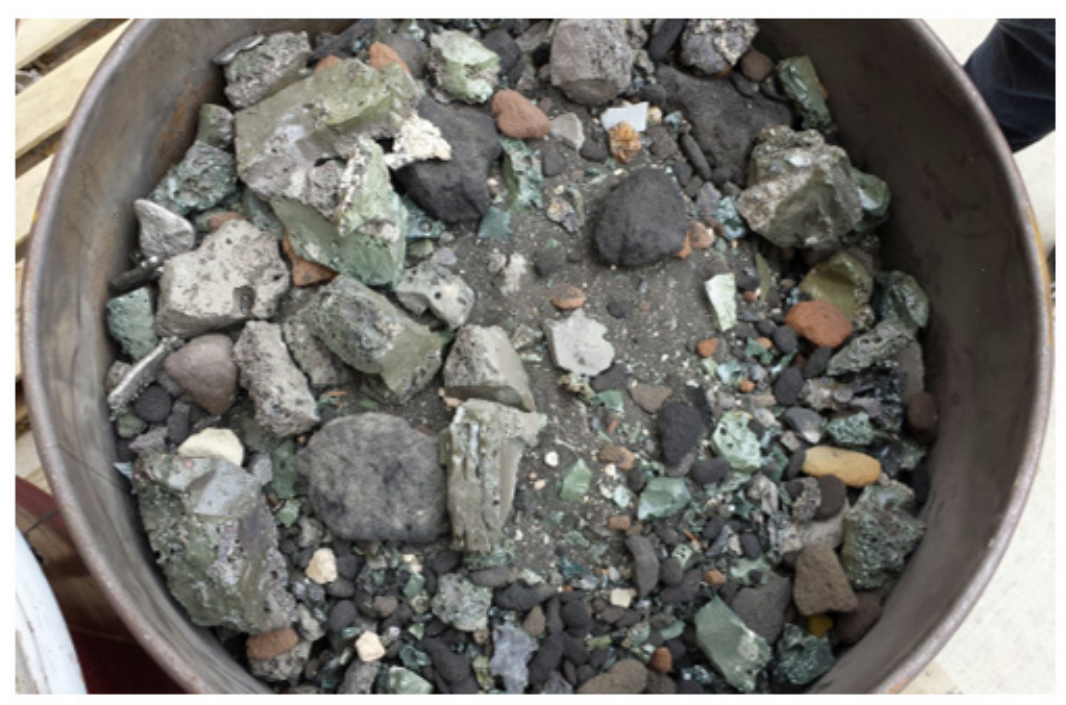

Figure 1: General Foundry Waste. 
Past studies have shown that both slag and spent foundry sand can be used in concrete production as aggregate or cement filler and in most cases the addition of this waste product improves the properties of the concrete $[1,2,5]$. These efforts have attributed to the percent foundry waste recycled annually, however; the impact is still low. There are two limiting factors to these studies that affect the contributing of an increase in the amount of foundry waste recycled annually. These factors are that these studies only utilize one foundry waste product, such as slag or spent foundry sand $[1,2]$. The other limiting factor is that these studies require the waste to be separated, debris free, and within a specific gradation in order to be included in concrete production. This degree of waste management produces a financial and labor burden on the foundries as their traditional practice is to stockpile their waste in one large stockpile, which is eventually discarded to the landfill [2]. Therefore, concrete users are detoured by the effort involved to utilize this waste product. Despite that, many researchers are still finding ways to separate and obtain either SPS or slag to be used in concrete materials to produce a more sustainable material. One study by Torres et al. [6] generalizes the foundry waste for use in concrete in order to increase the recycling percentage, by reducing processing time/cost and using all the waste produced by the foundry industry. This was done by partially replacing both fine aggregate and coarse aggregate of concrete with lightly processed foundry waste. Since foundry waste contains both fine and coarse materials, the as-received foundry waste was lightly processed and sieved to match the control concrete mixtures coarse and fine aggregate distribution. Both virgin coarse and fine aggregate were replaced by mass at $10 \%, 20 \%$, and $30 \%$. Two mixture groups replaced individual constituents separately (coarse and fine), and one mixture group replaced both coarse and fine in the same mixture. The compressive strength, splitting-tensile strength, flexural strength, and modulus of elasticity were measured for all groups at 7, 14, and 28 days. The results indicated that general foundry waste as either coarse, fine, or combined by mass replacement of natural aggregate has no impact on the mechanical performance of PCC up to $30 \%$ for individual replacement or $20 \%$ combined. This result not only demonstrates a possible avenue to increase the amount of foundry waste recycled annually, but it also reduces the demand for virgin aggregates, therefore a more sustainable concrete was developed.

Siddique et al. [1] completed a study using SFS in concrete as replacement of sand and reported an increase in compressive strength, splitting-tensile strength, flexural strength and modulus of elasticity of with an increase in used foundry sand content. The fine aggregate replacement used in their study consisted of three percentages $(10 \%, 20 \%$ and $30 \%)$. The increase in compressive strength varied from $8 \%$ and $19 \%$ depending upon the usedfoundry sand replacement and the age of the specimens. The percent increase for the splitting-tensile strength varied from $6.5 \%$ to $14.5 \%$ and $7 \%$ and for the flexural strength. Lastly the recorded performance increase for the modulus of elasticity varied from $5 \%$ to $12 \%$. Naik et al $[7,8]$ produced brick, blocks, paving stones and pre-cast molded concrete products all with the partial replacement or inclusions of Class F fly ash (an SCM), coal combustion bottom ash, and used foundry sand. The fine aggregate and Portland cement was replaced in two percentages, with used-foundry sand and fly ash respectively. The results showed an improvement on strength and durability. In the pre-cast molded concrete, the average compressive strength was $32 \%$ higher than the control samples. Bikas et al. [9] incorporated used foundry sand in asphalt concrete with $4 \%, 7 \%, 10 \%, 14 \%, 17 \%$, and $20 \%$ replacement of fine aggregate. Their tests measured the flow values and stability of the asphalt concrete. The results showed that a $10 \%$ replacement of fine aggregate with used-foundry sand is most suitable for asphalt concrete mixtures. Additionally, reported is that used-foundry sand did not affect the environment around the deposition. Yuksel et al. [10] used both bottom ash and non-ground blast furnace slag as $10 \%, 20 \%, 30 \%, 40 \%$ and $50 \%$ fine aggregate replacement, respectively. The results showed that both additives positively affect the durability properties of concrete, such as the resistance to high temperature and surface abrasion. This is due to the chemical and physical properties of the bottom ash and slag, as revealed by Scanning Electron Microscope (SEM) imaging. This work ultimately demonstrates that durable concrete can be produced with the addition of non-ground blast furnace slag and bottom ash.

Qasrawi et al. [11] uses both recycled concrete aggregate (RCA) and steel slag aggregate (SSA) as partial replacement in concrete. The results show a decrease in strength with full replacement, however a $67 \%$ replacement of SSA increased the properties of normal strength concrete. The use RCA had some adverse effects on the concrete such as workability, air content and modulus of elasticity, whereas the SSA replacement did not. All of these studies demonstrate, not only the current trend to use foundry waste in concrete, but also that the individual constituents of foundry waste can ultimately benefit the performance of concrete up to a certain percent replacement. These independent results provide credible insight into the use of foundry waste as a general constituent (combined or individually) in concrete to not only increase the percent of foundry waste recycled each year, but to increase the sustainability and possibly the performance of concrete materials.

\section{Acknowledgment}

None.

\section{Conflict of Interest}

No conflict of interest.

\section{References}

1. Siddique R, Schutter G, Noumowe A (2009) Effect of used-foundry sand on the mechanical properties of concrete. Constr Build Mater 23: 976980

2. Siddique R, Noumowe A (2008) Utilization of spent foundry sand in controlled low-strength materials and concrete. Resources, Conservation and Recycling 53: 27-35. 
3. Abichou, Benson C, Edil T (1998) Database on beneficial reuse of foundry by-products. Recycled materials in geotechnical applications. In: Vipulanandan C, Elton D (eds.) Geotechnical Special Publication 79: 210-223.

4. MOEE (1993) Spent foundry sand - alternative uses study. Report prepared by John Emery Geotechnical Engineering Limited for Ontario Ministry of the Environment and Energy and the Canadian Foundry Association. Queen's Printer for Ontario.

5. American Concrete Institute (2003) Ground Granulated Blast Furnace Slag as a Cementitious Constituent in Concrete, ACI 233R-03.

6. Torres A, Bartlett L, Pilgrim CU (2017) Effect of foundry waste on the mechanical properties of Portland Cement Concrete", Construction and Building Materials 135: 674-681.

7. Naik TR, Kraus RN, Chun YM, Ramme WB, Singh SS (2003) Properties of field manufactured cast-concrete products utilizing recycled materials. J Mater Civil Eng15(4): 400-407.
8. Naik TR, Kraus RN, Chun YM, Ramme WB, Siddique R (2004) Precast concrete products using industrial by-products. ACI Mater J 101(3):199206.

9. Bakis R, Koyuncu H, Demirbas A (2006) An investigation of waste foundry sand in asphalt concrete mixtures. Waste Manage Res 24: 269274.

10. Yuksel I, Bilir T, Ozkan O (2007) Durability of concrete incorporating non-ground blast furnace slag and bottom ash as fine aggregate. Build Environ 42: 2651-2659.

11. Qasrawi $H$ (2014) The use of steel slag aggregate to enhance the mechanical properties of recycled aggregate concrete and retain the environment. Const Build Mater 54: 298-304. 